\section{"It's in Your Hands-Prevent Sepsis in Health Care": 5 May 2018, World Health Organization (WHO) SAVE LIVES: Clean Your Hands Campaign}

To the Editor-Sepsis is a life-threatening organ dysfunction caused by a dysregulated host response to infection. ${ }^{1}$ It is estimated to affect more than 30 million people worldwide every year with high mortality and morbidity. ${ }^{2}$ Sepsis was reported as a key global health issue at the 70th World Health Assembly (WHA) in 2017, where a resolution on sepsis was adopted by member states. ${ }^{3}$

Sepsis can result from care practices and complicates healthcare-associated infections. Hand hygiene, a core of infection prevention and control (IPC), plays a critical role in preventing such avoidable events. ${ }^{4,5}$ Each year, the World Health Organization (WHO) "SAVE LIVES: Clean Your Hands" campaign aims to bring people together in support of hand hygiene improvement globally on or around May $5 .{ }^{6}$ In 2018, the campaign focuses on supporting the prevention of sepsis in health care. The WHO urges ministries of health, health facility leaders, IPC leaders, health workers, and patient advocacy groups to take action on hand hygiene to prevent sepsis in health care (Figure 1 and Supplemental Table 1).

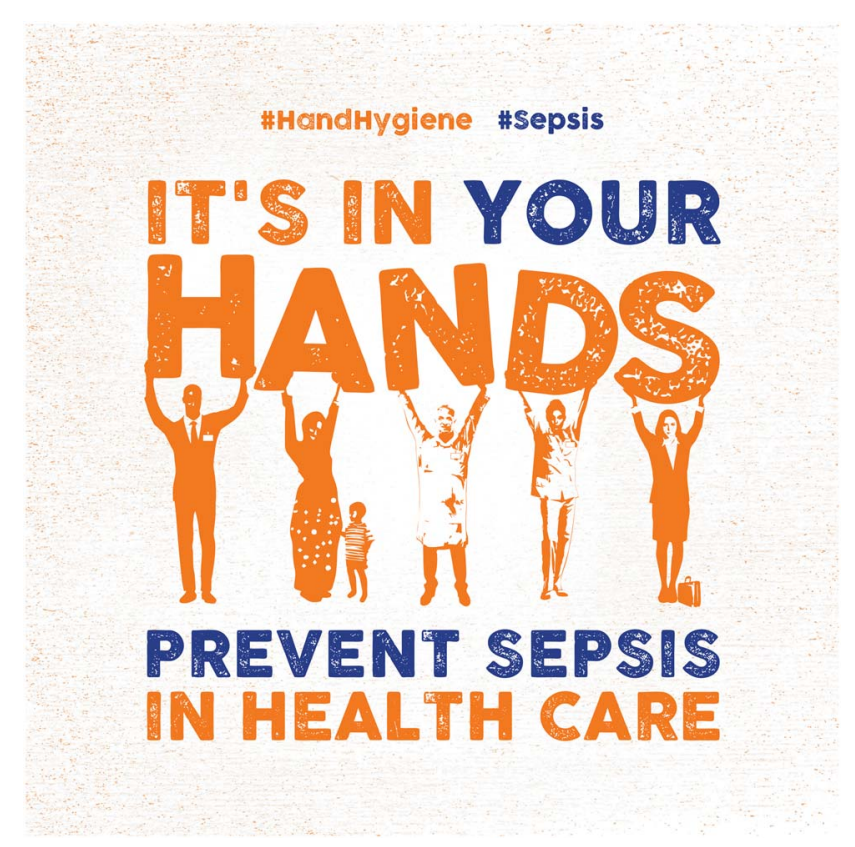

FIGURE 1. "It's in your hands-prevent sepsis in health care." 5 May 2018 World Health Organization (WHO) "SAVE LIVES: Clean Your Hands" campaign slogan and main promotional image (2018 hashtags: \#HandHygiene \#Sepsis). Campaign participants are invited to submit photos/selfies of them holding a board with the slogan and hashtags at www.CleanHandsSaveLives.org.
The WHO also invites health facilities to join the global campaign to demonstrate ongoing commitment to hand hygiene and IPC (http://www.who.int/infection-prevention/campaigns/ clean-hands/register/en/).

Each hand hygiene action contributes to preventing sepsis in health care: Let's act together, "It's in Your Hands-Prevent Sepsis in Health Care."

\section{ACKNOWLEDGMENTS}

The authors alone are responsible for the views expressed in this article, and they do not necessarily represent the views, decisions, or policies of the institutions with which they are affiliated.

Financial support: World Health Organization (WHO) and Infection Control Program and WHO Collaborating Centre on Patient Safety (SPCI/ WCC), University of Geneva Hospitals and Faculty of Medicine, Geneva, Switzerland. Hand hygiene research activities at the SPCI/WCC are supported by the Swiss National Science Foundation (grant no. 32003B_163262).

Potential conflicts of interest: All authors report no conflicts of interest relevant to this article.

\author{
Hiroki Saito, MD, MPH; ${ }^{1}$ \\ Tcheun Borzykowski, MSc; ${ }^{2}$ \\ Claire Kilpatrick, MSc; ${ }^{1}$ \\ Daniela Pires, MD; ${ }^{2,3}$ \\ Benedetta Allegranzi, MD; ${ }^{1}$ \\ Didier Pittet, MD, MS $^{2}$
}

Affiliations: 1. Infection Prevention and Control Global Unit, Department of Service Delivery and Safety, World Health Organization, Geneva, Switzerland; 2. Infection Control Programme and WHO Collaborating Centre on Patient Safety, University of Geneva Hospitals and Faculty of Medicine, Geneva, Switzerland; 3. Department of Infectious Diseases, Centro Hospitalar Lisboa Norte and Faculdade de Medicina da Universidade de Lisboa, Lisbon, Portugal.

Address correspondence to Prof Didier Pittet, MD, MS, Infection Control Programme and WHO Collaborating Centre on Patient Safety, University of Geneva Hospitals, 4 Rue Gabrielle-Perret-Gentil, 1211, Geneva, Switzerland (didier.pittet@hcuge.ch).

Infect Control Hosp Epidemiol 2018;39:634-635

(c) 2018 by The Society for Healthcare Epidemiology of America. All rights reserved. 0899-823X/2018/3905-0024. DOI: 10.1017/ice.2018.68

\section{SUPPLEMENTARY MATERIAL}

To view supplementary material for this article, please visit https://doi.org/10.1017/ice.2018.68

\section{REFERENCES}

1. Singer M, Deutschman CS, Seymour CW, et al. The third international consensus definitions for sepsis and septic shock (Sepsis-3). JAMA 2016;315:801-810.

2. Fleischmann C, Scherag A, Adhikari NK, et al. Assessment of global incidence and mortality of hospital-treated sepsis. Current estimates and limitations. Am J Respir Crit Care Med 2016;193:259-272.

3. Rhodes A, Evans LE, Alhazzani W, et al. Surviving Sepsis campaign: international guidelines for management of sepsis and septic shock: 2016. Intensive Care Med 2017;43:304-377. 
4. World Health Organization. WHO Guidelines on Hand Hygiene in Health Care. Geneva, Switzerland: World Health Organization; 2009.

5. World Health Organization. Guidelines on Core Components of Infection Prevention and Control Programmes at the National and Acute Health Care Facility Level. Geneva, Switzerland: World Health Organization; 2016.
6. SAVE LIVES: Clean Your Hands. WHO's Global Annual Campaign Advocacy Toolkit. World Health Organization website. http://www.who.int/gpsc/5may_advocacy-toolkit.pdf?ua=1. Published 2016. Accessed January 31, 2018. 